\title{
Northern Leaf Blight Response of Elite Maize Inbred Lines Adapted to the Mid-altitude Sub-humid Tropics
}

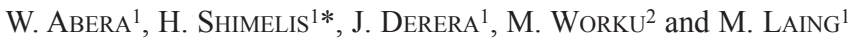 \\ ${ }^{1}$ African Centre for Crop Improvement, University of KwaZulu-Natal, Private Bag X01, \\ Scottsville 3209, Pietermaritzburg, South Africa \\ ${ }^{2}$ CIMMYT/Kenya, ICRAF House, P.O. Box 1041, Nairobi, Kenya \\ (Received 17 February 2015; Accepted 15 May 2015; \\ Communicated by A. Goyal)
}

\begin{abstract}
Productivity of maize (Zea mays L.) is curtailed by a number of stress factors, predominantly by diseases and insect pests. The Northern leaf blight disease of maize caused by Exserohilum turcicum (Pass.) Leonard and Suggs inflict significant yield losses in the humid tropical regions. The objectives of this study were to determine the leaf blight response of 50 elite maize inbred lines developed for the mid-altitude, sub-humid tropics and to select promising parents for resistance breeding. Inbred lines were evaluated in the field using a $5 \times 10$ alpha lattice design with three replications. Plants were artificially inoculated at the 4-6 leaf stages during 2011 and 2012. Data on disease severity and incidence, AUDPC and yields were recorded. Inbred lines had significant differences for E. turcicum reactions, and were classified into resistant, intermediate or susceptible categories. The mean disease severity ranged from $2.04 \%$ for the inbred line $136-$ a to $3.25 \%$ (Kuleni-C1-101-1-1-1). The upper leaf area infection of inbred lines $143-5-\mathrm{I}$ and $136-\mathrm{a}$ was $3.3 \%$, while the line Kuleni-C1-101-1-1-1 displayed 100\% infection. Further, 136-a developed the lowest AUDPC score at 238, whereas Kuleni-C1-101-1-1-1 had the maximum at 700. Overall, inbred lines CML202, 144-7-b, 139-5-j, 136-a, 30H83-7-1-1-1-2-1, ILoo'E-1-9-1-1-1-1-1 and 142-1-e, were identified as promising sources of resistance against E. turcicum. The selected elite inbred lines would be recommended for use in general varietal development, disease management and to enhance maize productivity, in the mid-altitude sub-humid tropics.
\end{abstract}

Keywords: Exserohilum turcicum, inbred line, leaf blight, maize, resistance breeding

\section{Introduction}

Maize (Zea mays L.) productivity is limited by a number of biotic and abiotic stresses. The major biotic stresses affecting maize productivity are infectious diseases, and field and storage pests, such as stem borer, weevils and termites (Agrios 2005; Hawbaker and Goodman 2006). The major diseases of maize include leaf blight caused by Exserohilum turcicum Pass Leonard \& Suggs, grey leaf spot (Cercospora zeae-maydis Tehon \& Dan- 
iels) and common leaf rust (Puccinia sorghi Schr.) (Pratt et al. 2003). Among the maize diseases, leaf blight, also known as northern corn leaf blight (NCLB) or Turcicum leaf blight, is the most widely spread, typically with disease incidence of 95-100\% and yield loss of up to $70 \%$ in the humid tropics (Bernardi et al. 2005). The disease causes changes in maize grain quality leading to decreased sugar content and reduced germination capacity. Heavily infected crop stands are predisposed to stalk rot (Bowen and Pedersen 1988; Cardwell et al. 1997; Muiru et al. 2007). In the humid tropics, such as in the mid-altitude sub-humid agro-ecologies of Ethiopia the disease is considered as a major problem of maize production (CIMMYT 2002; Wende et al. 2013).

Disease epidemics of the maize leaf blight are pronounced in constantly wet and humid growing areas. Therefore, strategic breeding to develop resistant varieties is crucial in regions where the disease reaches epidemic proportions (Dong et al. 2008). Different approaches are available to control maize leaf blight such as the use of host plant resistance, cultural practices, and fungicides (Dong et al. 2008). Host plant resistance is the cheapest and most effective way to control leaf blight disease; because chemical applications are expensive, environmentally unfriendly and often ineffective (Avila et al. 2004; Talukder et al. 2004). Field sanitation practices are difficult to implement. The use of leaf blight resistant maize varieties possessing qualitative or quantitative genes, in combination or separately, is the cheapest and most environmentally friendly method (Bernardi et al. 2005). Qualitative resistance is race-specific and governed by a single gene or few genes, whereas quantitative resistance is race-non-specific and polygenic (Singh et al. 2004; Bernardi et al. 2005). Qualitative maize leaf blight resistance genes designated as $H t 1, H t 2, H t 3, H t n$ and $H t m$ are reportedly dominant or partially dominant and confer nondurable resistance. The resistant genes are located on chromosomes 3, 5, and 8 (Welz and Geiger 2000; Wisser et al. 2008). This form of resistance may fail due to the emergence of virulent races of the pathogen through genetic mutation and recombination events (Freymark et al. 1994; Weilz and Geiger 2000; Bernardi et al. 2005). The E. turcicum exhibits a wide range of variability and new races attacking previously resistant varieties are well-documented (Lipps et al. 1997; Bernardi et al. 2005).

Breeding for resistance or tolerance to E. turcicum is the most economically viable control option for resource-constrained farmers. This is achieved through incorporation of resistance genes into existing elite genotypes. The option serves as one of the major components in the integrated management of the maize leaf blight. Disease severity, disease incidence, lesion size, and area under disease progress curve are the most common parameters used in the evaluation of maize genotypes for resistance to Turcicum leaf blight (Adipala 1994; Pratt et al. 2003). The objectives of this study were to determine the leaf blight response of 50 elite maize inbred lines developed for the mid-altitude sub-humid tropics, and to select promising parents for resistance breeding. The selected inbred lines may be used to develop hybrids with good resistance to leaf blight disease of maize. 


\section{Materials and Methods}

\section{Plant material and study site}

The study used 50 elite maize inbred lines adapted to the mid-altitude sub-humid tropical agro-ecologies. The lines were acquired from the Ethiopian maize research program (Bako) and the International Maize and Wheat Improvement Center (CIMMYT)

Table 1. Descriptions of the inbred lines used in this study

\begin{tabular}{|c|c|c|c|c|c|}
\hline No. & Name/pedigree & Sources $^{\mathrm{a}}$ & No. & Name/pedigree & Sources $^{\mathrm{a}}$ \\
\hline 1 & CML395 & CIMMYT & 26 & Kuleni-0080-4-2-1-1-1-1 & Bako \\
\hline 2 & Pool9A-4-4-1-1-1 & Bako & 27 & A7033 & Bako \\
\hline 3 & Gibe-1-158-1-1-1-1 & Bako & 28 & ILoo'E-1-9-1-1-1-1-1 & Bako \\
\hline 4 & 124-b(109) & Bako & 29 & Gibe-1-186-2-2-1 & Bako \\
\hline 5 & $\mathrm{SC} 22$ & Bako & 30 & F7215 & Bako \\
\hline 6 & Iloo'E-1-12-4-1-1 & Bako & 31 & CML 464 & CIMMYT \\
\hline 7 & $30 \mathrm{H} 83-7-1-1-1-2-1$ & Bako & 32 & CML 445 & CIMMYT \\
\hline 8 & DE-78-Z-126-3-2-2-1-1 & Bako & 33 & SC-715-154-1-1 & Bako \\
\hline 9 & $139-5-\mathrm{j}$ & Bako & 34 & $136-\mathrm{a}$ & Bako \\
\hline 10 & (LZ-955459/LZ955357)-B-1-B-B & Bako & 35 & CML 444 & CIMMYT \\
\hline 11 & SZSYNA-99-F2-3-6-2-1 & Bako & 36 & SZSYNA-99-F2-81-4-3-1 & Bako \\
\hline 12 & CML442 & CIMMYT & 37 & BH6609(F2)-10-2-1-2-1 & Bako \\
\hline 13 & $30 \mathrm{H} 83-7-1-5-1-1-1-1$ & Bako & 38 & CML 197 & CIMMYT \\
\hline 14 & Gibe-1-20-2-2-1-1 & Bako & 39 & SZSYNA-99-F2-80-3-4-1 & Bako \\
\hline 15 & $30 \mathrm{H} 83-56-1-1-1-1-1$ & Bako & 40 & DE-78-Z-126-3-2-1-2-1 & Bako \\
\hline 16 & Gibe-1-91-1-1-1-1 & Bako & 41 & X1264DW-1-2-1-1-1-1 & Bako \\
\hline 17 & SZSYNA-99-F2-2-7-3-1-1 & Bako & 42 & Poo19A-128-5-1-1-1 & Bako \\
\hline 18 & CML 202 & CIMMYT & 43 & Iloo’E-5-5-3-1 & Bako \\
\hline 19 & CML 312 & CIMMYT & 44 & $\mathrm{SC}-22-430(63)$ & Bako \\
\hline 20 & SC-715-121-1-3 & Bako & 45 & 124-b(113) & Bako \\
\hline 21 & SC-715-13-2-1 & Bako & 46 & $144-7-b$ & Bako \\
\hline 22 & $142-1-\mathrm{e}$ & Bako & 47 & CML 443 & CIMMYT \\
\hline 23 & $\begin{array}{l}\text { (CML 205/CML208//CML 202)-X2-1-2-B- } \\
\text { B-B }\end{array}$ & $\begin{array}{l}\text { CIMMYT } \\
\text { \& Bako }\end{array}$ & 48 & $30 \mathrm{H} 83-5-1-4-2-1-1$ & Bako \\
\hline 24 & (DRB-F2-60-1-2)-B-1-B-B-B & Bako & 49 & $143-5-\mathrm{I}$ & Bako \\
\hline 25 & DE-105-Z-126-30-1-2-2-1 & Bako & 50 & Kuleni-C1-101-1-1-1 & Bako \\
\hline
\end{tabular}

${ }^{a}$ Bako $=$ Bako national maize research coordination centre; CIMMYT $=$ International Maize and Wheat Improvement Centre. 
(Table 1). Inbred line CML197, which was sourced from CIMMYT, served as a susceptible check. All the lines are genetically stable and homozygous, and they were descended through continuous controlled self-pollination at Bako Research Station in Ethiopia.

The study was conducted at Bako Research Station in Ethiopia. The station is the national maize research coordination centre, situated at an altitude of 1650 metre above sea level, longitude $37^{\circ} 09^{\prime} \mathrm{E}$, latitude $09^{\circ} 06^{\prime} \mathrm{N}$ and has a nitosol soil type. It receives annual rainfall of $>1200 \mathrm{~mm}$. Bako area is one of the major maize producing environments in the country, representing the mid-altitude sub-humid agro-ecological zone.

\section{Field experiments}

The inbred lines were evaluated using a $5 \times 10$ alpha lattice design with three replications. Trials were conducted for two years (2011 and 2012) between May and September each year. Each plot was $5.1 \mathrm{~m}$ in length with three rows. The inter-row spacing was $75 \mathrm{~cm}$ and intra-row spacing was $30 \mathrm{~cm}$. Phosphorus $\left(100 \mathrm{~kg} \mathrm{ha}^{-1}\right)$ was applied once at planting. Nitrogen fertilizer was applied at $100 \mathrm{~kg} \mathrm{ha}^{-1}$ in two splits: half at planting and the remainder at 37 days after emergence. All the trial management practices were standard to the Bako Research Station.

\section{Leaf blight inoculum collection and preparation}

Isolates of E. turcicum were obtained from diseased maize samples collected from maize fields where the disease is prevalent. The infected leaves were cut into small sections $\left(1 \mathrm{~cm}^{2}\right)$ and surface sterilized using $2.5 \%$ sodium hypochlorite for 2-3 minutes. The plant tissues were then rinsed with sterile distilled water, blot dried and plated on to PDA in Petri dishes and incubated at room temperature for 3-4 days. Pure cultures were prepared by sub-culturing from the isolation plates. The cultures were incubated for 7-10 days to obtain sufficient growth. Inoculum was prepared by flooding the cultures with sterile distilled water, scraping the surface with microscopic slides to dislodge the conidia and then filtered using cheese cloth. The concentration of the conidia suspension was then adjusted to $10^{5}$ conidia per $\mathrm{ml}$ using a haemocytometer.

\section{Leaf blight inoculation}

Field grown maize plants were inoculated at 4-6 leaf stage of growth during mid-July, the middle of the main rainy season in Ethiopia. Inoculations were accomplished by spraying the maize plant with the conidia suspension until runoff using a hand atomizer. The inoculation was done late in the afternoon when there was sufficient moisture in the air. To promote conditions which are favourable for the disease development, fine water was sprayed as a mist over the inoculated plants. 


\section{Data collection and analysis}

\section{Disease assessment}

Leaf blight of maize inbred lines was visually assessed in the field at 2-3 weeks after inoculation in both years. Ten randomly selected plants were tagged and used for successive disease assessments. Plants were rated at 10 days interval for percent incidence, lesion length, and lesion width. Lesion sizes (expressed in centimetres) of two lesions of the 10 plants were measured at 10-day intervals to determine the rate of lesion expansion. Monitored lesions were marked with marker so that lesion could be traced and measured.

Disease severity was rated using the CIMMYT's method (www.CIMMYT.org) with 1-5 scoring scale: where

$1.0=$ very slightly infected, one or two restricted lesion on lower leaves or trace.

$2.0=$ slight to moderate infection on lower leaves, a few scatter lesions on lower leaves.

3.0 $=$ abundant lesions on lower leaves, a few on middle leaves.

$4.0=$ abundant lesions on lower and middle leaves extending to upper leaves.

$5.0=$ abundant lesions on all leaves, plant may be prematurely killed by blight.

\section{The area under disease progress curve (AUDPC)}

Data on leaf blight was recorded at ten-day intervals starting from disease onset for seven times each year during the growing period. To ensure consistent disease evaluation in the field, a disease progress curve was drawn. This curve was developed from 10 days severity reading in both years. By constructing a curve, symptom development and disease severity were compared over years. The area under disease progress curve was used to quantify the beginning of the epidemic and the time until the blight reached its peak. The derived disease parameter, AUDPC was calculated according to the equation of Campbell and Madden (1991) using the following formula:

$$
A U D P C=\sum_{i=1}^{n-1} \frac{\left(y_{i}+y_{i+1}\right)\left(t_{i+1}-t_{i}\right)}{2} ;
$$

where $n$ is the number of observations, $t_{i}$ days after planting for the ith disease assessment and $y_{i}$ disease severity. The disease progress curve represents an integration of all host, pathogen and environmental effects occurring during disease development and provides an opportunity for greater in depth analysis, when comparing small differences among test entries.

\section{Yield and thousand seed weight}

Grain yield ( $\mathrm{t} \mathrm{ha}^{-1}$ ) was calculated using the average shelling percentage of $80 \%$ adjusted to $12.5 \%$ grain moisture content. Data on grain yield was analysed with GenStat release 14.2 computer software, VSN International Ltd (Payne et al. 2008). Analysis of variance 
was done for the individual trials as well as combined analysis for the two years. Thousand seed weight (in gram) was measured from a random sample of 1000 seeds of each inbred line. Analysis of variance of all the disease and agronomic data were conducted using the GenStat release 14.2 computer software program (Payne et al. 2008).

\section{Results}

\section{Disease development}

Disease ratings significantly varied among the tested maize inbred lines $(p<0.001)$ both for severity and lesion length. Out of the 50 inbred lines tested during the two years, 11 were found to be resistant, 26 intermediate, and 13 susceptible with mean disease severity rating of 2.48. Tables 2 and 3 summarised the most 10 resistant and 10 susceptible inbred lines during both years. Mean values of the disease assessments varied across years and inbred lines. The effects of year, line and their interactions were highly significant $(p<0.001)$ for grain yield, disease severity and incidence. The disease incidences on susceptible inbred lines were high and reached a maximum of $88.48 \%$ in the susceptible control line CML-197 (Table 2), while on the resistant inbred lines (SZSYNA99-F2-81-4-3-1, 144-7-b, 30H83-7-1-1-1-2-1 and CML 202) the incidence was lower at the end of the growing period during the two years of evaluation (Tables 2 and 3). No accession was immune to leaf blight, but inbred lines such as CML197, SC-22-430(63), Kuleni-C1-101-1-1-1, SC22 and 124b (109) were the most susceptible (Tables 2 and 3).

\section{Lesion length}

There were highly significant differences $(p<0.001)$ for lesion length among inbred lines tested in 2011 and 2012. Pool9A-4-4-1-1-1, SZSYNA-99-F2-80-3-4-1 and CML 197 had larger lesion length than other inbred lines, whereas the lesion length of CML 202 and CML 312 was consistently small in both years, indicating their resistant reaction to the disease (Tables 2 and 3).

\section{Disease severity and AUDPC}

Disease severity scores of the inbred lines in both years were significantly different $(p<0.01)$ (Tables 2 and 3). During the two testing years, inbred lines with low severity score were CML 202, 144-7-b, and 142-1-e. Inbred lines with high severity scores reflecting their susceptibility were CML 197, Kuleni-C1-101-1-1-1, and SC-22-430 (Tables 2 and 3). Final severity score and AUDPC value provided adequate evaluations of the resistance of inbred lines to E. turcicum (Table 3). AUDPC was significantly different for different lines $(p \leq 0.001)$. Higher area under disease progress curves were recorded for susceptible than resistant lines (Table 2).

Considering the AUDPC values, the inbred lines, which were identified as susceptible, included Kuleni-C1-101-1-1-1, Pool9A-4-4-1-1-1, and A7033 with extremely high val- 

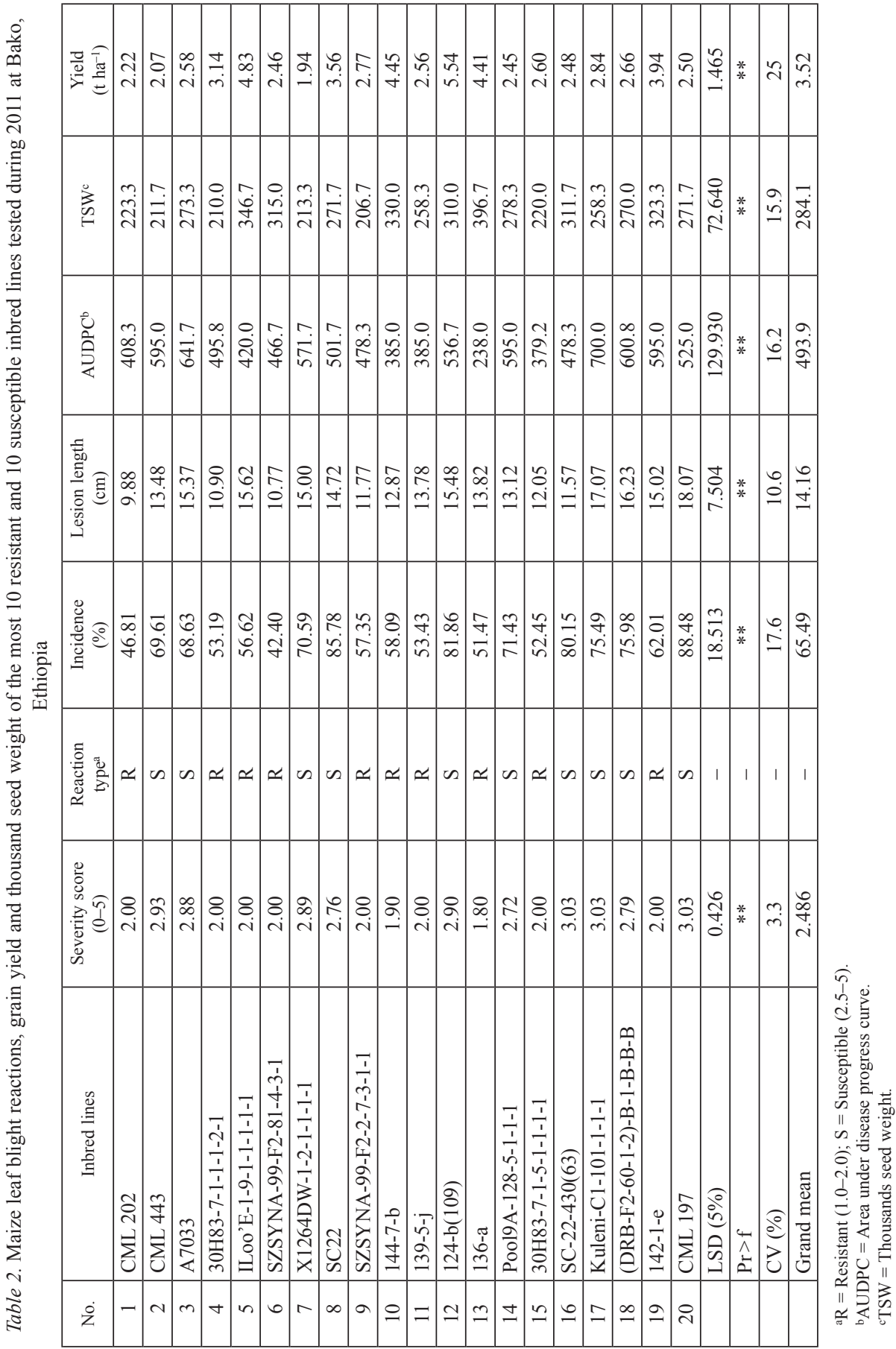


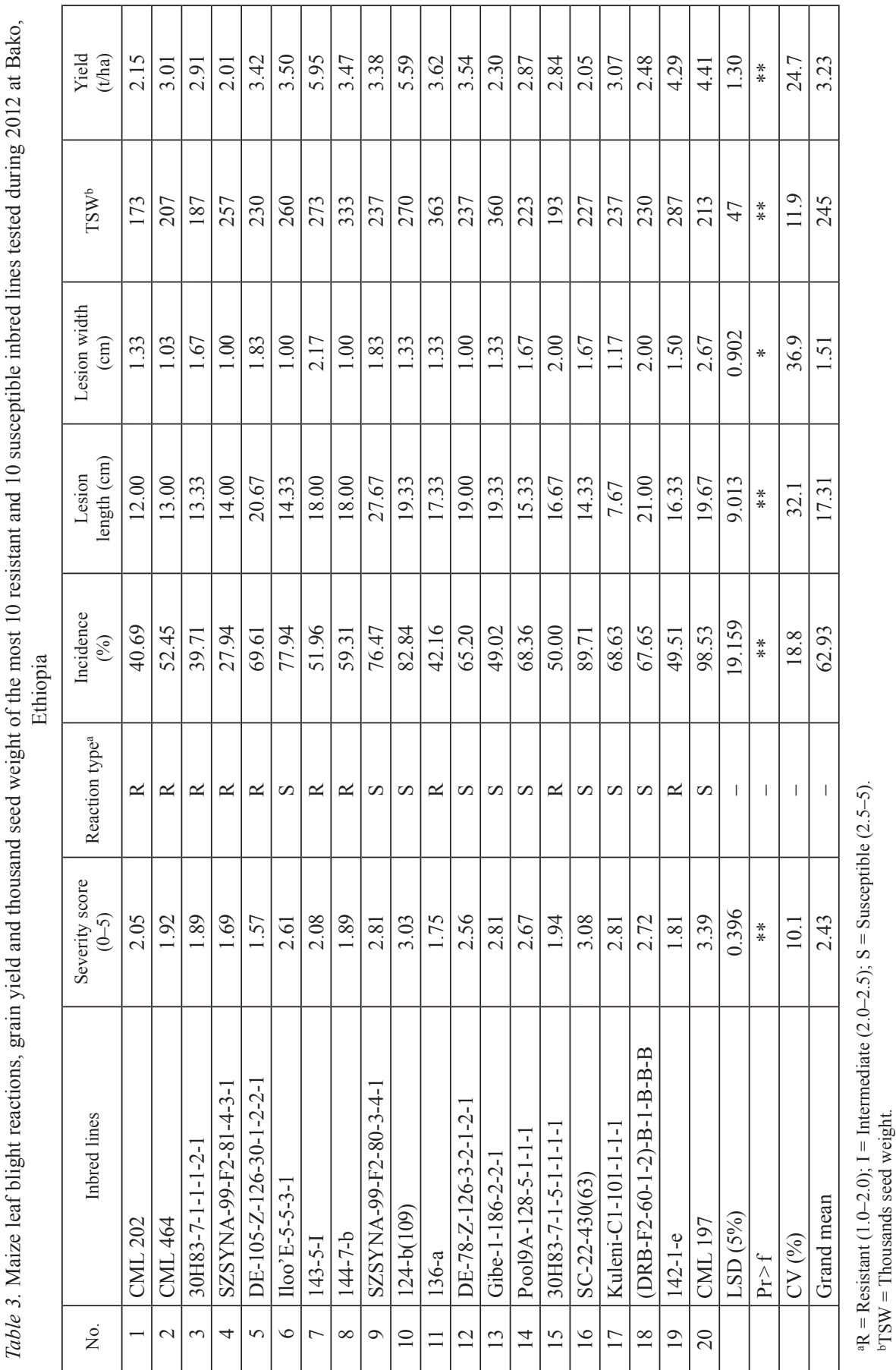


ues of 700,671 , and 642 , in that order. Lines identified as resistant, such as 136a and Gibe-1-186-2-2-1, displayed consistently lower AUDPC values of 238 and 350, respectively (data not shown). The severity of the disease was slightly higher in 2011 than 2012. This might be associated with lower rainfall at flowering in 2012, which created unfavourable conditions for blight development. However, the environmental conditions were generally favourable for northern leaf blight development during both years, which was adequate for discriminating the lines according to resistance.

\section{Correlation of disease parameters and agronomic traits}

There were significant and positive relationships $(p<0.05)$ between the disease parameters and agronomic traits (Table 4). Non-significant and negative correlations existed between AUDPC and thousand seed weight $(r=-0.26, p<0.09)$, indicating that disease level correlated with a reduced seed weight (Table 4).

Correlations of disease parameters with yield and seed weight were determined for years 2011 and 2012 (Table 4). There were significantly negative and non-significant correlations between the disease parameters and thousand seed weight in both years. Yield had weak and non-significant positive correlations with the disease parameters (Table 4) during both years. This indicates that all the parameters effectively measured disease progress which had a negative effect on yield and seed weight.

Table 4. Pair-wise Pearson correlation matrixes among selected agronomic and disease parameters in 50 maize inbred tested for NCLB reactions, in 2011 (top) and in 2012 (bottom)

\begin{tabular}{|c|c|c|c|c|c|}
\hline & $\mathrm{TSW}^{\mathrm{a}}$ & AUDPC $^{b}$ & Incidence & Lesion length & Severity \\
\hline TSW & 1 & & & & \\
\hline AUDPC & $-0.26^{*}$ & 1 & & & \\
\hline Incidence & $-0.05 n s$ & $0.54 * *$ & 1 & & \\
\hline Lesion length & $0.31 \mathrm{~ns}$ & $0.36^{* *}$ & $0.43 * *$ & 1 & \\
\hline Severity & $-0.08 n s$ & $0.67 * *$ & $0.85^{* *}$ & $0.41 * *$ & 1 \\
\hline Yield & $0.51 *$ & $-0.09 \mathrm{~ns}$ & $0.09 \mathrm{~ns}$ & $0.34 * *$ & $-0.13 n s$ \\
\hline $\mathrm{TSW}^{\mathrm{a}}$ & 1 & & & & \\
\hline Incidence & $-0.14_{\mathrm{ns}}$ & 1 & & & \\
\hline Lesion width & $-0.02_{\mathrm{ns}}$ & $0.38^{* *}$ & 1 & & \\
\hline Lesion length & $0.35_{\mathrm{ns}}$ & $0.32^{*}$ & $0.34^{*}$ & 1 & \\
\hline Severity & $-0.16_{\mathrm{ns}}$ & $0.75^{* *}$ & $0.24_{\mathrm{ns}}$ & $0.14_{\text {ns }}$ & 1 \\
\hline Yield & $0.30^{* * *}$ & $0.32_{\mathrm{ns}}$ & $0.31_{\mathrm{ns}}$ & $0.40^{*}$ & $-0.03_{\mathrm{ns}}$ \\
\hline & TSW & incidence & lesion width & lesion length & Severity \\
\hline
\end{tabular}

aTWS $=$ Thousand seed weight; ${ }^{\mathrm{b}} \mathrm{AUDPC}=$ Area under disease progress curve; $*$ and $* *$ denote significant correlation at $p=0.05$ and $p=0.01$, respectively; ns $=$ non-significant correlation. 


\section{Spanning tree for disease assessment parametrs}

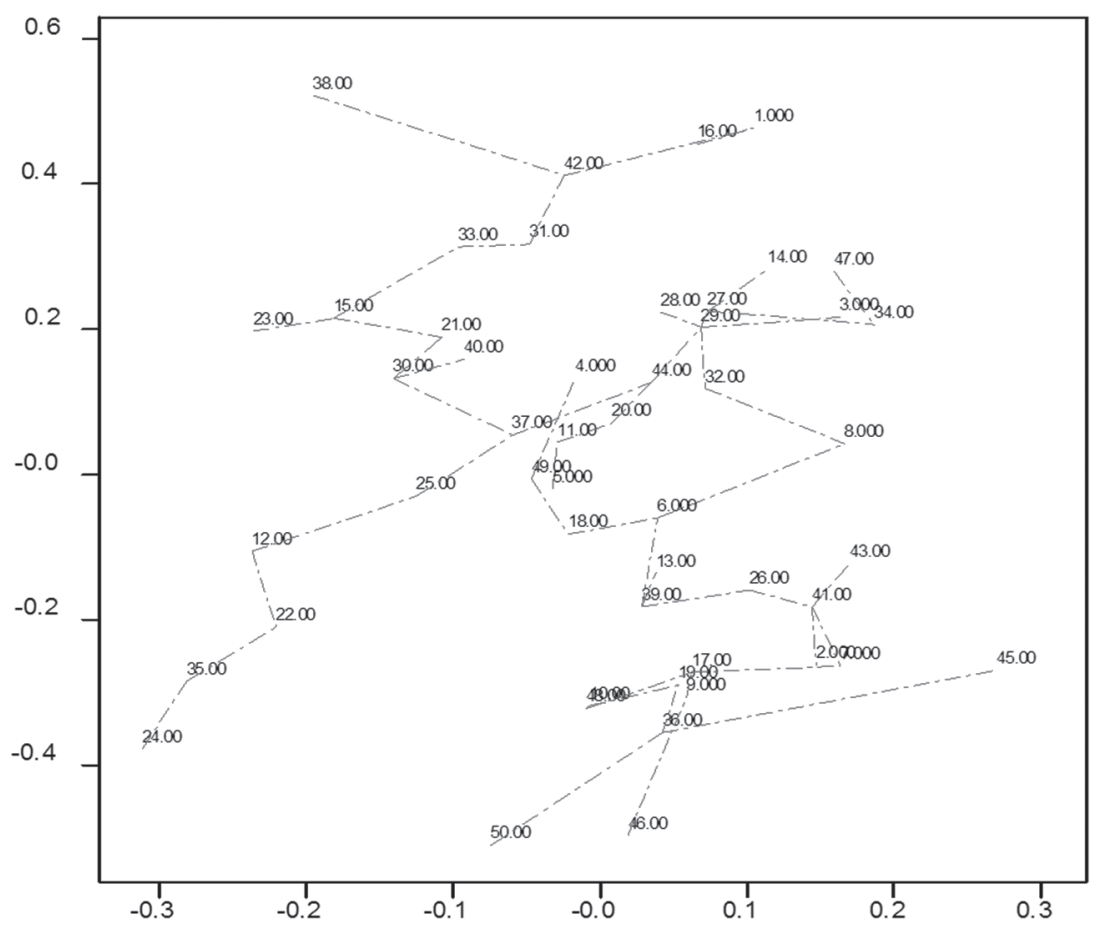

Figure 1. Clustering trees of 50 elite maize inbred lines for their reaction to leaf blight using four disease parameters: AUDPC, disease severity, incidence and lesion length

The minimum spanning tree (Fig. 1) conveniently clustered the tested inbred lines, using the four disease parameters in this study (AUDPC, disease severity, incidence and lesion length). Accordingly, inbred lines with similar reaction types were positioned on the same branch (Fig. 1). Among the inbred lines, the most susceptible ones were CML197 (entry 50), Kuleni-C1-101-1-1-1(46), and 124-b (109) (36) which were allocated on the same branch. These lines were susceptible for the four disease parameters. Line CML197, a susceptible check in the trial was allocated to this group. Resistant inbred lines, such as CML202, and pool9A-128-5-1-1-1, were allocated on the same position in the tree (Fig. 1). The resistant inbred lines will be used to incorporate leaf blight resistance in new maize hybrids and for gene deployment in the mid-altitude humid tropics.

\section{Discussion}

The varying reaction to the disease among the tested maize inbred lines indicates the presence of both resistant and susceptible genotypes. Muriithi and Mutinda (2001) reported the presence of resistance to E. turcicum in maize germplasm. The author described re- 
duced percent leaf area infected and small lesion size as manifestations of resistance to the maize blight disease. The significant differences detected among the genotypes in this study across years are attributable to factors affecting the development of leaf blight disease in maize. Among the factors are favourable climatic conditions, genotypic difference, inoculation method employed and proper disease rating. Levy (1991) indicated that for northern leaf blight development, pathogenic fitness, environmental conditions and proper methods of inoculation were the most important factors.

Previous studies of Muiru et al. (2007) showed that dropper inoculation was efficient and eliminated chance of disease escape. The present study found that this inoculation technique (spraying a conidiae suspension) was easy to employ and reliable. Clear differences were notable between inbred lines, as the lesions on resistant accessions remained at the point of inoculation, whereas on the intermediate entries, the size of lesion was relatively small. During the flowering period, their ratings remained relatively low and constant, but the susceptible genotypes exhibited a moderate increase in diseased leaf tissue. Selection of less susceptible individual progenies can result in the accumulation of additive minor genes for resistance following designed crosses, thereby increasing the level of quantitative resistance (Bowen and Pedersen 1988; Ceballos et al. 1991; Ojulong et al. 1996; Pratt et al. 1997).

The present study identified inbred lines CML202, 144-7-b, 139-5-j, 136-a, 30H83-71-1-1-2-1, ILoo'E-1-9-1-1-1-1-1 and 142-1-e as promising sources of resistance against E. turcicum. One of the most popular parental inbred line, $124-\mathrm{b}$ (109) was susceptible to NCLB (Table 3). However, due to the late appearance of the disease, i.e., after flowering there was no pronounced yield penalty. Consequently, the inbred line appeared to be one of the high yielding test inbred lines (Table 3). CIMMYT (2004) reported that the time of NCLB infection were the most important factor in determining grain yield response in maize. The selected elite inbred lines would be recommended for use in general varietal development, disease management and to enhance maize productivity, in the mid-altitude sub-humid tropics.

\section{Acknowledgements}

The Alliance for a Green Revolution in Africa (AGRA) is sincerely thanked for financial support of the study. The Ethiopian Institute of Agricultural Research (EIAR) is acknowledged for providing the first author's leave of absence and for hosting the field research. The all-round support provided by the national maize research program of Ethiopia is highly appreciated. The International Maize and Wheat Improvement Center (CIMMYT) is sincerely thanked for providing some of the inbred lines.

\section{References}

Adipala, E. 1994. Reaction of 13 maize genotypes to E. turcicum in different agro-ecological zones of Uganda. East Afr. Agric. J. 59:213-218.

Agrios, G.N. 2005. Plant Pathology $5^{\text {th }}$ Ed. Academic Press. Amsterdam, the Netherlands. 
Avila, C.M., Satovic, Z., Sillero, J.C., Rubiales, D., Moreno, M.T., Pauls, K.P., Torres A.M. 2004. Isolate and organ-specific QTLs for ascochyta blight resistance in faba bean (Vicia faba L). Theor. Appl. Genet. 108:1071-1078.

Bernardi Ogliari, J., Guimarães, M.A., Geraldi, I.O., Camargo, L.E.A. 2005. New resistance genes in the Zea mays-Exserohilum turcicum pathosystem. Genet. Mol. Biol. 28:435-439.

Bowen, K.L., Pedersen, W.L. 1988. Effects of northern leaf blight components on corn inbreds. Plant Disease 72:952-956.

Campbell, C.L., Madden, L.V. 1991. Introduction to Plant Disease Epidemiology. John Wiley and Sons. New York, USA.

Cardwell, K.F., Schulthess, F., Ndehma, R., Ngoko, Z. 1997. A systems approach to assess crop health and maize yield loss due to pests and diseases. Cameroon Agri. Ecosystems Env. 65:33-47.

Ceballos, H., Deutsch, J.A., Gutiérrez, H. 1991. Recurrent selection for resistance to Exserohilum turcicum in eight subtropical maize populations. Crop Sci. 31:964-971.

CIMMYT 2002. Annual Report. International Maize and Wheat Improvement Center (CIMMYT), Mexico.

CIMMYT 2004. A guide for field identification. $4^{\text {th }}$ Ed. Mexico, D.F., Mexico.

Dong, J., Fan, Y., Gui, X., An, X., Ma, J., Dong, Z. 2008. Geographic distribution and genetic analysis of physiological races of Setosphaeria turcica in northern China. Am. J. Agr. Biol. Science 3:389-398.

Freymark, P.J., Lee, M., Martinson, C.A., Woodman, W.L. 1994. Molecular marker facilitated investigation of host plant response to E. turcicum in maize (Zea mays L.). Theor. Appl. Genet. 88:305-313.

Hawbaker, M.S., Goodman, M.M. 2006. Resistance of temperately adapted tropical inbred lines and testcrosses to three important maize pathogens. Maydica 51:135-139.

Levy, Y. 1991. Variation in fitness among field isolates of Exserohilum turcicum in Israel. Plant Dis. 75:163166.

Lipps, P.E., Pratt, R.C., Hakiza, J.J. 1997. Interaction of Ht and partial resistance to Exserohilum turcicum in maize. Plant Dis. 81:277-282.

Muiru, W.M., Mutitu, W.E., Kemenju, J.W. 2007. Reaction of some Kenyan maize genotypes to Turcicum leaf blight under greenhouse and field conditions. Asian J. Plant Sci. 6:1190-1196.

Muriithi, L.M., Mutinda, C.J.M. 2001. Genetic variability of maize genotypes for resistance to exerohilium turcicum in Kenya. Seventh Eastern and Southern Africa Regional Maize Conference. $11^{\text {th }}-15^{\text {th }}$ February 2001. Online available at: apps.cimmyt.org

Ojulong, H.F., Adipala, E., Rubaihayo, P.R. 1996. Diallel analysis for reaction to Exserohilum turcicum of maize cultivars and crosses. Afr. Crop Sci. J. 4:19-27.

Payne, R.W., Murray, D.A., Harding, S.A., Baird, D.B., Soutar, D.M. 2008. GenStat for Windows $\left(11^{\text {th }}\right.$ Edition). VSN International, Hemel Hempstead, UK.

Pratt, R.C., Gordon, K., Lipps, P., Asea, G., Bigirwa, G., Pixley, K. 2003. Use of IPM in the control of multiple diseases of maize. Afr. Crop Sci. J. 11:189-198.

Pratt, R.C., Lipps, P.E., Sango, F., Hakiza, J.J., Adipala, E. 1997. Inheritance of race non-specific resistance to Exserohilum turcicum in maize synthetic population OhS10. Afr. Crop Sci. J. 1:55-63.

Singh, R., Mam, V.P., Koranga, K.S., Bisht, G.S., Khandelwal, R.S., Bhandar, P., Pan, S.K. 2004. Identification of additional sources of resistance to Exserohilum turcicum in maize. Sabrao J. Breeding Genet. 36:45-47.

Talukder, Z.I., Tharreau, D., Price, A.H. 2004. Quantitative trait loci analysis suggests that partial resistance to rice blast is mostly determined by race-specific interactions. New Phytol. 162:197-209.

Welz, H.G., Geiger, H.H. 2000. Genes for resistance to northern corn leaf blight in diverse maize populations. Plant Breeding 119:1-14.

Wende, A., Hussein, S., Derera, J., Mosisa, W., Laing, M.D. 2013. Preferences and constraints of maize farmers in the development and adoption of improved varieties in the mid-altitude, sub-humid agro-ecology of western Ethiopia. Afr. J. Agric. Res. 8:1245-1254.

Wisser, R.J., Balint-Kurt, P.J., Nelson, R.J. 2008. The genetic architecture of disease resistance in maize: A synthesis of published studies. Phytopathol. 96:120-129. 